\title{
Pathogenic variation and virulence related responses of Ascochyta lentis on lentil
}

\author{
P. Sambasivam ${ }^{\mathrm{AB}}$, P.W.J. Taylor ${ }^{\mathrm{A}}$ and R. Ford ${ }^{\mathrm{A}}$
}

Faculty of Veterinary and Agricultural Sciences, The University of Melbourne, Parkville, Victoria 3010

${ }^{\mathrm{B}}$ Corresponding author- e-mail prabhakaran.thanjavur@unimelb.edu.au, Phone: +61425622050; Fax +61383445037

\begin{abstract}
Ascochyta blight of lentil (Lens culinaris ssp. culinaris) is caused by Ascochyta lentis. The disease causes severe damage to all aerial parts of the plant and may lead to total crop loss during extremely severe epidemics. To identify qualitative differences in resistance within Australian lentil crops, variation in virulence was examined among 17 isolates of A. lentis on six differential lentil genotypes (ILL7537, ILL5588 ( $c v$. Northfield), ILL6002, ILL5722 ( $c v$. Digger), ILL481 ( $c v$. Indianhead) and CIPA203 ( $c v$. Nipper)). Six distinct virulence patterns were identified, with Pathotype I (AL4) being highly virulent, causing disease on all genotypes except ILL7537 and pathotype VI (Kewell) exhibiting low virulence on all genotypes. Histopathology studies were carried out to further understand interaction differences between isolate-host combinations and add to the knowledge of possible resistance mechanisms underlying lentil's defence to the pathogen. The infection process was compared between lentil genotypes with different levels of resistance and isolates with different levels of virulence. Microscopic and biochemical differences were observed between compatible and incompatible interactions, which were related to timeafter-inoculation, with slower responses noted in susceptible lentil genotypes. Relatively fast release of reactive oxygen species (ROS) and a subsequent hypersensitive response (HR) was central to initial defence at the point of penetration in the most resistant lentil genotypes.
\end{abstract}

Key words: Lentil, ascochyta blight, Ascochyta lentis, pathotype, infection, host resistance

\section{Introduction}

Ascochyta blight, caused by the fungus Ascochyta lentis, is a major biotic constraint to lentil (Lens culinaris ssp. culinaris) production in Australia and worldwide (Kaiser et al., 1997). The pathogen decreases productivity through infection and damage to leaves, stems, roots and pods; and reduces marketability by discolouring the seed (Taylor et al., 2007).

The fungus may either be seed-borne or survive on infected stubble from previous diseased crops. Movement of the host germplasm has disseminated the pathogen worldwide (Kaiser 1997) where it is primarily introduced to new sites through infected seed (Morrall and Sheppard 1981; Kaiser and Hannan 1986; Nasir and Bretag 1997b). Wind dispersal of spores from infected lentil stubble in neighbouring fields is a likely source of new infections (Hawthorne et al. 2012). Splash dispersal of asexual pycnidiospores in prolonged damp conditions leads to epidemics". 
Improving and sustaining lentil resistance is an important priority to decrease the need for application of fungicides. In order to develop effective and durable resistance breeding strategies to a particular pathogen such as A. lentis, a good understanding of the variation in the pathogen's ability to cause disease and potential to evolve/adapt is required. Such understanding of the pathogen population is crucial for determining the effectiveness of novel and currently used resistance sources and to gauge their potential lifespan (Muehlbauer and Chen, 2007; Taylor and Ford, 2007). This should include information on the overall genetic relatedness among isolates from the same and different lentil growing regions, as well as the ability of individual isolates to cause disease on lentil under a pre-defined and controlled environment (Tivoli et al., 2006). One method to categorize fungal isolates for their potential to cause disease is to assess their ability to infect and produce symptoms on a set of host genotypes with a previously reported range of susceptibility/resistance statuses for which differing underlying genetic inheritance and potential different resistance mechanism are known. In this manner, isolates can be categorized into "pathotype groups" based on qualitative differences in the infection of genotypes (Taylor and Ford, 2007). For this, a set of host genotypes with known differential disease reactions is required, together with an appropriate and reproducible screening method.

Previous studies have shown pathogenic variation among A. lentis isolates on various sets of genotypes. In Canada, Kemal and Morrall (1995) tested the reaction of 28 A. lentis isolates across 10 lentil genotypes and concluded that significant differences existed in disease reactions between isolates and host genotypes. The field screening of seven A. lentis isolates in 1994 and 1995 in Canada also showed significant difference in isolate pathogenicity between cropping seasons (Ahmed and Morrall, 1996). Nasir and Bretag (1997b) assessed the ability of 39 isolates of A. lentis isolates from Australia to cause disease on 22 lentil genotypes and subsequently grouped isolates into six pathotypes, each with a distinct virulence pattern. In another study, Nasir and Bretag (1998) grouped 219 isolates into 14 pathotypes. Russell and Hill (1997) also reported significant differences in interaction between lentil lines and A. lentis isolates. Similarly, Hussain et al. (1999) grouped 20 A. lentis isolates into five pathotypes based on the reactions of seven lentil genotypes following inoculation and Iqbal et al. (2006) grouped nine A. lentis isolates into five pathotypes based on disease symptoms produced on 10 lentil genotypes. However, these studies did not include indepth qualitative biological evidence of differences among the host responses to the isolates screened. True differences in virulence (and subsequent potential pathotype labelling) would require evidence of distinctly different biological defence responses induced among different isolates across the host set. Such evidence may be gained through careful microscopic or genomic dissection of the interactions.

The different findings on pathogenic variation within A. lentis populations within and between countries and lentil growing regions may highlight significant differences in the population structures among these regions and certainly reflects the different host genotypes used; hence these studies cannot be directly compared. Also, it is unlikely that the exact same bioassay conditions (host genotypes; inoculation loads; 
temperature or growth conditions) or disease scoring systems were used among the studies. These factors may have a significant effect on the way in which the pathogen-host interaction is measured and would make it unwise to compare studies directly. Recently, Banniza and Vandenberg (2006) reported that 65 Canadian A. lentis isolates could not be placed into pathotype groups, since the difference among them was proposed to be due to natural variation of virulence in the population and hence a continuum of pathogenicity. However, through more in-depth analyses, it may be possible to identify qualitative differences in the disease reactions and the underlying resistance gene responses that may lead to more accurate pathotyping for the purposes of choosing isolates for selective resistance breeding.

In order to determine true differences in the ability of isolates to cause disease across host genotypes carrying potentially different resistance sources, a highly reproducible bioassay and initial symptom scoring method is required. Although, field screening provides an efficient and economical method for testing large numbers of host genotypes, glasshouse-based screening techniques are a more reliable method because they are performed in controlled environmental conditions and use uniform inoculum application (Tivoli et al., 2006). Artificial screening under controlled conditions was successfully used in earlier studies to distinguish host reactions to A. lentis isolates (Nasir and Bretag, 1997d; Ford et al., 1999; Hussain et al., 1999; Nguyen et al., 2001). If different pathotypes are identified, it will be very important to include representatives of these for accurate resistance screening of lentil germplasm, to identify not only potential novel resistance sources but also check that existing resistances will prevail when and if exposed to greater pathotype diversity (Ye et al., 2002).

Prior to investigation of the molecular responses of the host resistance, cytological studies of the hostpathogen interaction can help identify the early events that occur during infection and ultimately lead to a better understanding of the resistance mechanism (Dita et al., 2007). Previously, conidia germination, formation of appressoria and penetration were studied during the infection process of the highly virulent and low virulent ascomycete Colletotrichum lentis (formerly C. truncatum; Damm et al., 2014) on partially resistant and susceptible genotypes of lentil (Chongo et al., 2002). Selection of robust resistance within breeding programs would be improved following characterisation of the biological responses of the host to isolates representative of the range of virulence within the fungal population, together with knowledge on the genetic mechanisms underpinning the defence responses.

Recognition of an avirulent pathogen and subsequent action of disease resistance (R) genes may induce a biphasic reactive oxygen species (ROS) accumulation with a small, non-specific transient first phase, followed by a continuous second phase with much higher intensity that is associated with disease resistance (Lamb and Dixon, 1997; Torres et al., 2006). ROS are proposed to play a number of crucial roles in activating the defence responses in host pathogen interactions, including strengthening of plant cell walls, hypersensitive response and activation of defence-related proteins and genes (Huckelhoven and Kogel, 2003; Li et al., 2005). Association of the oxidative burst with disease resistance has been reported 
in several legume species such as chickpea (Coram and Pang, 2006), faba bean (Maurin et al., 1993) and Medicago truncatula (Foster-Hartnett et al., 2007), and previously in lentil (Mustafa et al., 2009). Although browning at the margin of lesions has been reported (Roundhill et al., 1995), very little is known about the timing and genotype specificity of the oxidative burst mechanism in lentil in response to A. lentis.

Roundhill et al. (1995) reported that conidia of A. lentis germinated within 6 hours post-inoculation (hpi), and produced germ tubes and appressoria by $10 \mathrm{hpi}$, and cytoplasm aggregated adjacent to the infection hyphae. Within $40 \mathrm{hpi}$, the plasmalemma broke down and cells were occupied by the fungus with only remnants of the protoplasm. Mustafa et al. (2009) showed that molecular responses to A. lentis were well under way at 6 hpi. An in-depth microscopic study of the timing of underlying and very early (including prior to $6 \mathrm{hpi}$ ) physiological and biochemical defence responses has never been conducted before. Information from such a study would help to provide physiological association with any subsequent molecular differential expression data in the early host-pathogen interaction. By assessing for differences in the reactions among high virulent and low virulent isolates on resistant and susceptible genotypes, more evidence will be provided of potential pathotype groups within the fungus population.

The objectives of this study were to: 1) characterize the diversity in virulence among Australian A. lentis isolates on a set of lentil genotypes with previously characterized mechanisms of resistance, or susceptibility, and 2) determine key virulence-related responses of A. lentis through the assessment of physiological and/or biochemical factors on a differential host set.

\section{Materials and methods}

\section{Virulence of Australian A. lentis on a differential set of lentil genotypes}

Plants and fungal isolates

The differential set used comprised six lentil genotypes: ILL7537, ILL5588 ( $c v$. Northfield), ILL6002, ILL5722 ( $c v$. Digger), ILL481 ( $c v$. Indianhead) and CIPA203 ( $c v$. Nipper). The rationale for their inclusion is provided in Table 1. Seed was provided by the Victorian Department of Primary and Environmental Industries (DEPI), Horsham, Australia and sown in $10 \mathrm{~cm}$ diameter pots with 3 seeds/pot/replication (3 replicates per host genotype/isolate) and pots were filled with pine bark soil and a slow releasing fertilizer, Osmocote ${ }^{\circledR}$. Plants were grown in a growth chamber maintained at $20 \pm 1{ }^{\circ} \mathrm{C}$ with a $16 / 8 \mathrm{~h}($ light/dark) photoperiod and watered every alternate day. A fast nutrient releasing fertilizer Aquasol® $(0.8 \mathrm{~g} / \mathrm{L})$ was applied at weekly intervals. Seventeen single-spored fungal isolates were supplied by DEPI, Horsham, Victoria, Australia (Table 2). 
Table 1. Host genotypes and their current ranking to Ascochyta lentis in Australia

\begin{tabular}{|l|l|l|}
\hline Genotype & Resistance ranking & Citation \\
\hline ILL7537 & R & Nasir (1998); Ford et al. (1999) \\
\hline Nipper & MR-R & Pulse Australia (2011) \\
\hline ILL5588 & MR & Nasir (1998); Ford et al. (1999) \\
\hline Indianhead & MR & Andrahennadi (1997) \\
\hline Digger & MR-S & Department of Primary Industries (2012) \\
\hline ILL6002 & S & Nasir (1998); Ford et al. (1999) \\
\hline
\end{tabular}

Table 2. Ascochyta lentis isolates used in this study.

\begin{tabular}{|l|l|l|l|}
\hline Isolate & Description & Origin & Month and Year \\
\hline 1 & AL3 & Horsham, Victoria & Dec 1998 \\
\hline 2 & AL4 & Horsham, Victoria & Dec 1998 \\
\hline 3 & AL5 & Horsham, Victoria & Dec 1998 \\
\hline 4 & AL9 & Horsham, Victoria & Dec 1998 \\
\hline 5 & AL16 & Horsham, Victoria & Dec 1998 \\
\hline 6 & AL39 & Horsham, Victoria & Dec 1998 \\
\hline 7 & AL41 & Horsham, Victoria & Dec 1998 \\
\hline 8 & AL43 & Horsham, Victoria & Dec 1998 \\
\hline 9 & AL50 & Horsham, Victoria & Dec 1998 \\
\hline 10 & Alford A.A & Alford, South Australia & Dec 2001 \\
\hline 11 & Kewell & Kewell, Victoria & Dec 2001 \\
\hline 12 & L2RK1-05 & Kingsford, South Australia & May 2006 \\
\hline 13 & L2RK1-05 2-8-4 & Kingsford, South Australia & July 2006 \\
\hline 14 & L3RYE-05 & Yeelanna, South Australia & May 2006 \\
\hline 15 & L3RYE-05 1-1-1 & Yeelanna, South Australia & July 2006 \\
\hline 16 & LDHO-05 & Horsham, Victoria & May 2006 \\
\hline 17 & LIGHO-05 1-6-7 & Horsham, Victoria & July 2006 \\
\hline
\end{tabular}

\section{Preparation of inoculum and bioassay}

The spore suspension used as inoculum in bioassays was prepared from 14-day-old fungal cultures grown on potato dextrose agar (PDA) in an incubator with $12 / 12 \mathrm{~h}$ near ultra-violet light/dark cycles $28{ }^{\circ} \mathrm{C}$. Cultures were flooded with sterile distilled water and pycnidia were scraped with a sterile bent glass rod to release pycnidiospores. The spore suspension was then filtered through four layers of muslin cloth and the spore density was determined using a haemocytometer and adjusted to $10^{5}$ spores $\mathrm{mL}^{-1}$. Tween $20(0.02 \%$ $\mathrm{v} / \mathrm{v}$ ) was added to the suspension as a surfactant and 14-day-old seedlings were sprayed with a fine mist of inoculum until run-off using an air-pressured hand-held sprayer. Each inoculated plant was immediately covered with an inverted plastic cup (mini-dome technique developed by Chen et al. (2005)) to maintain 100\% humidity to induce optimum spore germination and infection (Nasir and Bretag, 1997d). After $48 \mathrm{~h}$, the plastic cups were removed and the plants were transferred to the growth chamber (conditions as above). The plants were misted daily with water to maintain favorable conditions for disease development. 


\section{Disease assessment}

Disease assessment was made at 7,14 and 21 days after inoculation (DAI). A non-destructive whole-plant 1-9 scoring system was used based on leaf and stem symptoms (Ford et al., 1999). Only the 21 DAI data was used for subsequent statistical analysis as this was when expression of disease symptoms was first visualized reliably on all hosts.

\section{Pathotyping of isolates}

The six lentil genotypes ILL7537, ILL5588 (cv. Northfield), ILL6002, ILL5722 (cv. Digger), ILL481 (cv. Indianhead) and CIPA203 (cv. Nipper) were used as differentials to separate the isolates of A. lentis into pathotype groups based on their difference in disease severity rating (R, MR, and S) observed at 21 DAI (Nasir and Bretag 1997a; Iqbal et al., 2006). The differentials were chosen based on the known differences in simple inheritance of the resistance trait as well as a highly susceptible (add reference).

\section{Data analysis}

At $21 \mathrm{DAI}$, plants with a mean disease score of 3 or less were considered resistant since leaf lesions that developed did not produce pycnidia and no stem lesions developed; hence these plants could potentially outgrow the disease and survive; and no inoculum would be available to re-infect the crop. Plants with a mean score of 5 were considered moderately resistant since, although stem lesions had developed, no pycnidia were produced in any of the lesions on leaves or stems. Those plants with a mean score of 7 and above were considered susceptible as pycnidia were produced in both leaf and stem lesions. These phenotypic cut-offs had previously been used to determine the Mendelian genetic inheritance of A. lentis resistance (Ford et al., 1999; Nguyen et al., 2001) and for mapping of R-QTL (Rubeena et al., 2006). Data were analyzed using two-way analysis of variance (ANOVA) in MINITAB 15 (Minitab Inc, USA).

\section{Physiological and/or biochemical differences among the lentil/A. lentis interactions}

Plants, fungal isolates and inoculum preparation

Seed of genotypes ILL7537, ILL5588 (cv. Northfield) and ILL6002 were grown as described above. Single-spored A. lentis isolates AL4 (high virulence) and Kewell (low virulence) were established and inoculum prepared as described above.

\section{Inoculation and sample collection}

Fully expanded lower leaves from 14-day-old plants were detached for inoculation at each time point. The detached leaves were surface sterilised by immersing them in a $70 \%$ ethanol solution for 30-60 sec. and then gently dried with cotton wool. The five leaves from each plant were placed, abaxial surface facing upward, in a separate petri dish lined with moist filter paper to provide high relative humidity. One drop $(\sim 10 \mu \mathrm{L})$ of a spore suspension of $10^{5}$ conidia $\mathrm{mL}^{-1}$ was applied using a micropipette to the middle section of the abaxial surface of each detached leaf. Petri dishes were sealed with parafilm and samples were incubated for $2,6,12,24,36$ or $48 \mathrm{~h}$ at $20^{\circ} \mathrm{C}$ in the dark. 


\section{Fixation and clearing of leaf sample}

Inoculated leaf tissues were fixed and cleared as described by Achuo et al. (2003) with the following modifications: the leaf tissue was immersed in a clearing solution (ethanol:glacial acetic acid; 1:2 V/V) for $24 \mathrm{~h}$ to remove chlorophyll. The solution was then removed using a sterile pipette and replaced with fresh clearing solution for another 12 to $24 \mathrm{~h}$ (Khan and Hsiang, 2003). The cleared leaves were stored in lactic acid/ glycerol/ water (1:1:1V/V/V) until microscopic examination.

\section{Visualisation of fungal structures}

Fungal structures were visualised by staining the cleared leaf tissue with lacto-phenol cotton blue (Sigma Aldrich) for $5 \mathrm{~min}$ or tryphan blue (0.05\%; Sigma Aldrich) in a phosphate buffer for $10 \mathrm{~min}$. The stained leaf tissue was washed in 50\% ethanol or distilled water for 2 to 3 times in order to remove the excess dye. The leaf tissues were then mounted in water on a glass microscope slide and covered with a cover slip. The samples were examined with a Leica DMRBE light microscope fitted with a Leica DC300F digital camera. Images were captured using Leica IM50 v.4 software.

\section{Evaluation of development of infection structures among lentil cultivars}

Spore germination, germ tube length and appressoria formation of each of the isolates were assessed on the detached leaves of each lentil genotype. Spore germination was measured at 2 and 6 hpi, germ tube length was measured at 2, 6, 12 and 24 hpi and appressoria formation was measured at 6,12 and 24 hpi. For this, four independent leaves were collected at each time point (one from each of four plants) per isolate/host interaction. For each leaf, observations were taken at locations close to each of the four corners. In total, 16 observations were made for each interaction at each time point. Also, a total of 100 spores were examined for each interaction at each time point ( 25 spores per corner) to calculate the spore germination and appressoria formation percentages. A spore was considered as germinated when a germination tube was present, regardless of length or number of germ tubes per spore. All globular structures with a diameter larger than that of the germination tube or hyphae of origin were considered an appressoria (Dita et al., 2007). At 2, 6, 12 and 24 hpi another set of leaf tissues were stained as previously described. Images of three conidia were randomly selected from a single leaf from each of four replicate plants and germ tube length was measured using Leica IM50 v.4 software.

Spore germination, germ tube length and appressoria formation data were square root transformed prior to statistical analysis and graphs were presented with original back transformed percentage data. Significant differences were identified via analysis of variance (ANOVA) within the Genstat software package (10th edition, VSN International Limited, United Kingdom).

\section{Histochemical detection of Reactive Oxygen Species (ROS)}

The production of $\mathrm{H}_{2} \mathrm{O}_{2}$ in lentil leaves of the genotypes ILL6002, ILL5588 and ILL7537 in response to $A$. lentis isolates Kewell and AL4, was detected using the 3-3, diaminobenzidine (DAB, Sigma-Aldrich, 
USA) uptake method (Thordal-Christensen et al., 1997; Vancker et al., 2000). Briefly, detached leaves of the three host genotypes that were inoculated with each of the A. lentis isolates as described previously were incubated for 2, 4, 6, 8, 12, 24, 36 and 48 hpi following inoculation. Segments $(1.0 \times 0.5 \mathrm{~cm})$ of inoculated leaf tissue were then excised (five replicates per host genotype/isolate combination) using a sterile razor blade and immediately immersed in a $1 \mathrm{mg} \mathrm{ml}^{-1} \mathrm{DAB} \mathrm{HCl}(\mathrm{pH} 3.8)$ solution and left for $8 \mathrm{~h}$ in the dark at room temperature. The segments were then fixed and cleared and stained with tryphan blue or lacto phenol cotton blue as previously described. Tissues were examined for $\mathrm{H}_{2} \mathrm{O}_{2}$ accumulation as an indication of hypersensitive response (HR) at the locations of hyphae penetration and the surrounding cells. $\mathrm{H}_{2} \mathrm{O}_{2}$ was detected as a reddish brown colouration in the DAB treated tissue and visualised under light microscope.

\section{Results}

\section{Differential reaction of lentil genotypes to $A$. lentis isolates}

Generally, the mean disease score increased at each time point on each host genotype. At 7 DAI, most genotypes were resistant with the exception of ILL6002, which was moderately resistant to 11 isolates (Table 3). At 14 DAI, ILL6002 was susceptible to 16 isolates and only ILL7537 and CIPAL203 ( $c v$. Nipper) remained resistant to all isolates. At 21 DAI, stem girdling was observed in ILL6002 and Digger. At the same stage, stem lesions were commonly observed in ILL5588 and Indianhead but rarely in Nipper. No stem lesion or girdling was observed in ILL7537 throughout the term of the experiment. The analysis of variance showed highly significant differences between lentil lines $(\mathrm{p}=<.001)$, between A. lentis isolates $(\mathrm{p}=<.001)$ and between all interactions $(\mathrm{p}=<.001)$ at this time point.

The mean disease scores from the controlled environment bioassays agreed with the published resistance/susceptibility rankings of the host genotypes, indicating the suitability of the bioassay for assessing differences in virulence among isolates. ILL6002 was susceptible (7-9) to all the isolates tested except to Kewell in which the host reaction was moderately resistant (5). Digger was susceptible (7) to 10 isolates and moderately resistant to seven isolates. Indianhead was classified as resistant (3) to moderately resistant to all the isolates. ILL5588 was moderately resistant to all isolates except Kewell to which it was resistant (3). Nipper was resistant (1-3) to 12 isolates and moderately resistant to five isolates. ILL7537 was resistant (1-3) to all the isolates tested. 
Table 3. The mean disease score of six lentil genotypes inoculated with 17 single-spored isolates of Ascochyta lentis at 7, 14 and 21 days after inoculation

\begin{tabular}{|c|c|c|c|c|c|c|c|c|c|c|c|c|c|c|c|c|c|c|}
\hline \multirow{2}{*}{ Isolates } & \multicolumn{3}{|c|}{ Digger } & \multicolumn{3}{|c|}{ ILL6002 } & \multicolumn{3}{|c|}{ Indianhead } & \multicolumn{3}{|c|}{ ILL5588 } & \multicolumn{3}{|c|}{ ILL7537 } & \multicolumn{3}{|c|}{ Nipper } \\
\hline & 7 & 14 & 21 & 7 & 14 & 21 & 7 & 14 & 21 & 7 & 14 & 21 & 7 & 14 & 21 & 7 & 14 & 21 \\
\hline AL3 & 3 & 5 & 7 & 3 & 7 & 7 & 1 & 3 & 5 & 1 & 3 & 5 & 1 & 1 & 3 & 1 & 1 & 3 \\
\hline AL4 & 3 & 5 & 7 & 5 & 5 & 7 & 1 & 3 & 5 & 1 & 3 & 5 & 1 & 3 & 3 & 1 & 3 & 3 \\
\hline AL 5 & 3 & 5 & 7 & 3 & 5 & 7 & 1 & 3 & 5 & 1 & 3 & 5 & 1 & 1 & 3 & 1 & 3 & 5 \\
\hline AL 9 & 3 & 5 & 7 & 3 & 5 & 7 & 1 & 3 & 5 & 3 & 3 & 5 & 1 & 1 & 3 & 1 & 1 & 3 \\
\hline AL16 & 3 & 3 & 5 & 3 & 5 & 7 & 1 & 3 & 3 & 1 & 3 & 5 & 1 & 1 & 3 & 1 & 3 & 3 \\
\hline AL39 & 3 & 5 & 5 & 3 & 5 & 7 & 1 & 3 & 5 & 1 & 3 & 5 & 1 & 1 & 3 & 1 & 3 & 3 \\
\hline AL41 & 3 & 7 & 7 & 3 & 5 & 7 & 3 & 5 & 5 & 3 & 5 & 5 & 1 & 1 & 3 & 1 & 3 & 5 \\
\hline AL43 & 3 & 3 & 5 & 3 & 5 & 7 & 1 & 3 & 3 & 1 & 3 & 5 & 1 & 1 & 1 & 1 & 3 & 3 \\
\hline AL50 & 3 & 5 & 7 & 3 & 5 & 7 & 3 & 5 & 5 & 1 & 3 & 5 & 1 & 1 & 3 & 1 & 3 & 5 \\
\hline Alford A.A & 1 & 5 & 5 & 3 & 5 & 7 & 3 & 3 & 5 & 1 & 3 & 5 & 1 & 1 & 1 & 1 & 1 & 3 \\
\hline Kewell & 1 & 3 & 5 & 3 & 3 & 5 & 1 & 3 & 3 & 1 & 3 & 3 & 1 & 1 & 1 & 1 & 1 & 1 \\
\hline L2RK1-05 & 3 & 5 & 7 & 5 & 5 & 7 & 1 & 3 & 5 & 1 & 3 & 5 & 1 & 3 & 3 & 1 & 3 & 3 \\
\hline L2RK1-05 2-8-4 & 3 & 5 & 5 & 5 & 7 & 7 & 3 & 3 & 5 & 3 & 3 & 5 & 1 & 1 & 1 & 3 & 3 & 5 \\
\hline L3RYE & 3 & 5 & 7 & 3 & 5 & 7 & 3 & 5 & 5 & 1 & 3 & 5 & 1 & 3 & 3 & 1 & 3 & 3 \\
\hline L3RYE-05 1-1-1 & 3 & 5 & 7 & 5 & 7 & 9 & 3 & 5 & 5 & 3 & 3 & 5 & 1 & 1 & 3 & 3 & 3 & 3 \\
\hline LDHO-05 & 3 & 3 & 5 & 5 & 5 & 7 & 1 & 3 & 5 & 1 & 3 & 5 & 1 & 3 & 3 & 1 & 3 & 3 \\
\hline LIGHO 05 1-6-7 & 3 & 5 & 7 & 5 & 5 & 7 & 3 & 5 & 5 & 3 & 3 & 5 & 1 & 3 & 3 & 3 & 3 & 5 \\
\hline
\end{tabular}




\section{A. lentis pathotype grouping}

The 17 isolates exhibited different virulence patterns when inoculated on the six different lentil genotypes of different reported resistance inheritance. Isolates were classified into six pathotype groups (Table 4) based on the ability to cause disease and severity of symptoms expressed on the differential host set at 21 DAI (Table 2). A summary of the host reactions of the genotypes to the pathotype groups is shown in Table 5 .

Table 4. Pathotype groupings among the 17 A. lentis isolates based on the disease score taken at 21 DAI.

\begin{tabular}{lll}
\hline Pathotype & Isolates & No. of isolates \\
\hline I & AL3, AL4, AL9, L2RK1-05, L3RYE, L3RYE 05-1-1-1 & 6 \\
II & AL5, AL41, AL50, LIGHO 05 1-6-7 & 4 \\
III & AL39, Alford A.A, LDHO-05 & 3 \\
IV & AL16, AL43 & 2 \\
V & L2RK1-05-2-8-4 & 1 \\
VI & Kewell & 1 \\
\hline
\end{tabular}

Table 5. A summary of reactions induced by 17 A. lentis pathotypes on six lentil genotypes at 21 dai.

\begin{tabular}{lllllll}
\hline \multirow{2}{*}{ Genotypes } & \multicolumn{5}{c}{ Disease Reaction to isolate pathotypes* } \\
\cline { 2 - 7 } & I & II & III & IV & V & VI \\
\hline Digger & S & S & MR & MR & MR & MR \\
ILL6002 & S & S & S & S & S & MR \\
Indianhead & MR & MR & MR & R & MR & R \\
ILL5588 & MR & MR & MR & MR & MR & R \\
ILL7537 & $\mathbf{R}$ & $\mathbf{R}$ & $\mathbf{R}$ & $\mathbf{R}$ & $\mathbf{R}$ & $\mathbf{R}$ \\
Nipper & $\mathbf{R}$ & MR & $\mathbf{R}$ & $\mathbf{R}$ & MR & $\mathbf{R}$ \\
\hline
\end{tabular}

*Where a disease reaction of 1,3 was classified as Resistant (R); 5 was moderately resistant (MR) and 7, 9 was susceptible (S).

Isolates in Pathotype groups I and II triggered similar reactions on all the lentil differentials except CIPAL203 ( $c v$. Nipper) which was moderately resistant to Pathotype group II isolates. Pathotype group III and IV isolates exhibited similar reactions on all the differentials except Indianhead, which was moderately resistant to Pathotype group III isolates. ILL5722 ( $c v$. Digger), ILL481 ( $c v$. Indianhead) and ILL5588 ( $c v$. Northfield) were moderately resistant, whereas ILL6002 was susceptible and CIPAL203 ( $c v$. Nipper) and ILL7537 were resistant to Pathotype group V isolates. Pathotype group VI (isolate Kewell) produced the lowest disease response across the host differentials. Four genotypes; (ILL7537, CIPAL203 ( $c v$. Nipper), ILL5588 ( $c v$. Northfield) and ILL481 ( $c v$. Indianhead) were resistant and ILL5722 ( $c v$. Digger) and ILL6002 were moderately resistant, indicating Kewell to be the least pathogenic of all of the isolates tested. 


\section{Quantification of infection process}

\section{Spore germination}

A significant difference in spore germination was detected between the high virulent isolate AL4 and the low virulent isolate Kewell on the resistant genotype ILL7537, the moderately resistant genotype ILL5588 and the susceptible genotype ILL6002 at 2 hpi (Fig. 1). At 2 hpi, a mean of 86\% of the AL4 spores had germinated on the three genotypes (Fig.1). In contrast, at $2 \mathrm{hpi}$, a mean of $76 \%$ of the Kewell spores had germinated on ILL6002 and ILL5588, however just 64\% of the Kewell spores had germinated on ILL7537. Spore germination percentage increased gradually for both isolates between 2 and 6 hpi at which time there was no significant difference on either ILL6002 or ILL5588 (Fig.1). However a significant difference remained on ILL7537 at 6 hpi with germination rates at $88 \%$ for Kewell and $96 \%$ for AL4.

\section{Germ tube growth}

The mean germ tube length of Kewell was significantly shorter than that of AL4 on each of the host genotypes at every time point assessed (Fig. 2).

\section{Appressorium formation}

\section{Timing of appressoria formation}

AL4 produced appressoria at 6 hpi on ILL6002 and ILL5588, whereas Kewell did not on any of the host genotypes until $12 \mathrm{hpi}$. Although both isolates eventually did produce appressoria, neither was able to form appressoria on ILL7537 before $12 \mathrm{hpi}$. Interestingly, almost three times as many AL4 spores formed appressoria on ILL6002 as on ILL7537 at 6 hpi (Fig. 3).

\section{Percent appressoria formation}

There was a significant difference between the isolates in appressoria formation on ILL6002, ILL5588 and ILL7537 at 12 hpi. On ILL6002, no Kewell spores and 60\% of the AL4 spores formed appressoria at 6 hpi and this percentage increased to $55 \%$ and $80 \%$, respectively at 12 hpi. On ILL5588, 21\% of Kewell spores and $28 \%$ of AL4 spores formed appressoria at 12 hpi. On ILL7537, 17\% of Kewell spores and 23\% of AL4 spores formed appressoria at 12 hpi (Fig. 3).

\section{Biochemical analysis of ROS generation}

Histochemical detection of ROS generation in response to low virulent isolate Kewell Hydrogen peroxide $\left(\mathrm{H}_{2} \mathrm{O}_{2}\right)$ was detected beneath appressoria of Kewell on ILL7537 as early as 20 hpi (Fig. 4A). This was observed on ILL5588 at $24 \mathrm{hpi}$. At $36 \mathrm{hpi}$ in ILL7537, $\mathrm{H}_{2} \mathrm{O}_{2}$ had accumulated at the penetration sites and also in papillae and vesicles in the surrounding epidermal cells (Fig. 4B and Fig. 4C). In addition to $\mathrm{H}_{2} \mathrm{O}_{2}$ production, other typical characteristics of HR were observed in ILL7537, such as a granular cytoplasm structure and thickening of involved cell walls (Fig. 4C). Similar but less frequent observations were seen in ILL5588, and never in ILL6002. 


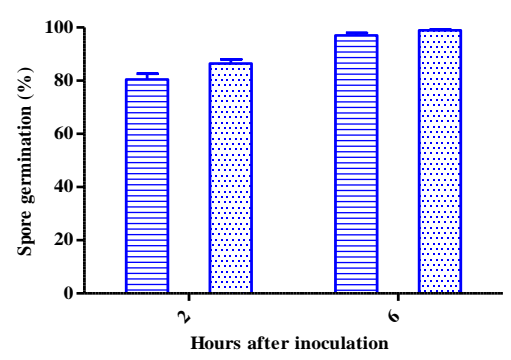

ILL6002 (S)
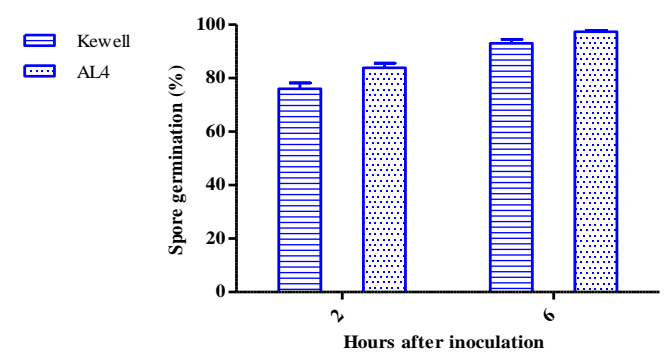

ILL5588 (MR)
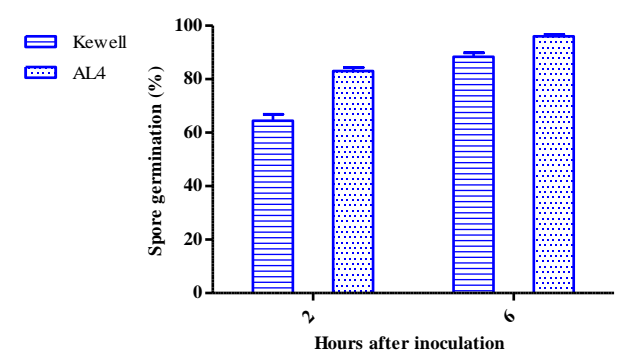

ILL7537 (R)

Fig. 1 Conidia germination (\%) at 2 and 6 hai

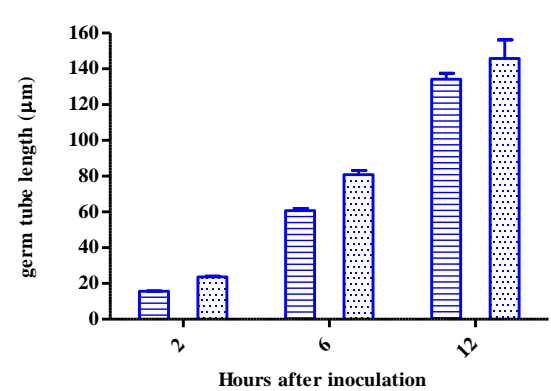

ILL6002 (S)

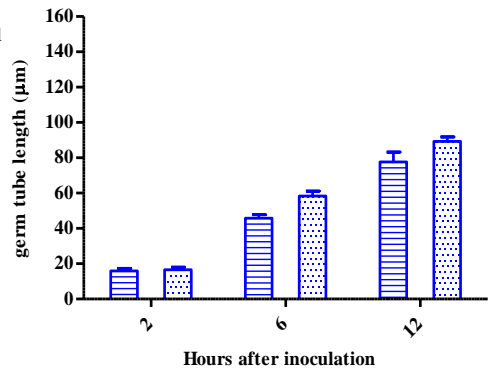

ILL5588 (MR)

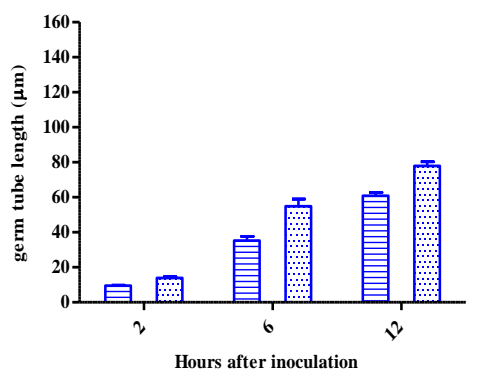

ILL7537 (R)

Fig. 2 Germ tube length $(\mu \mathrm{m})$ prior to appressoria formation at 2, 6 and 12 hai

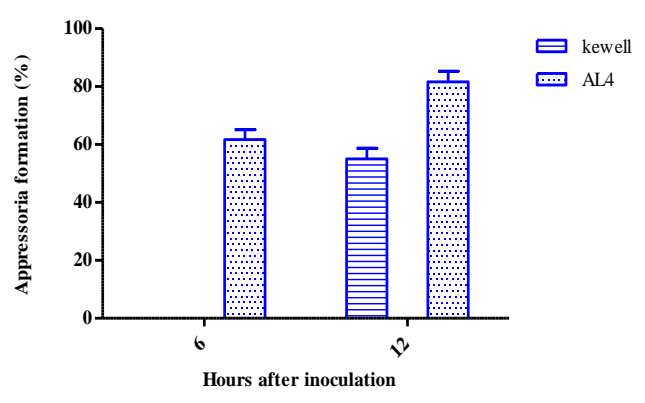

ILL6002 (S)

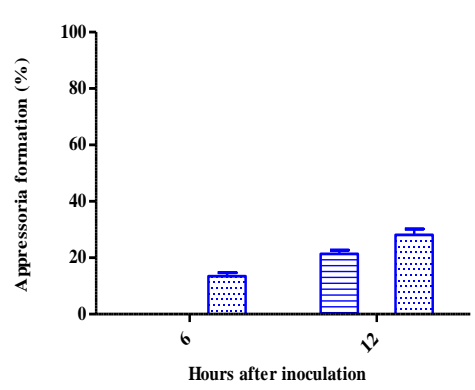

ILL5588 (MS)

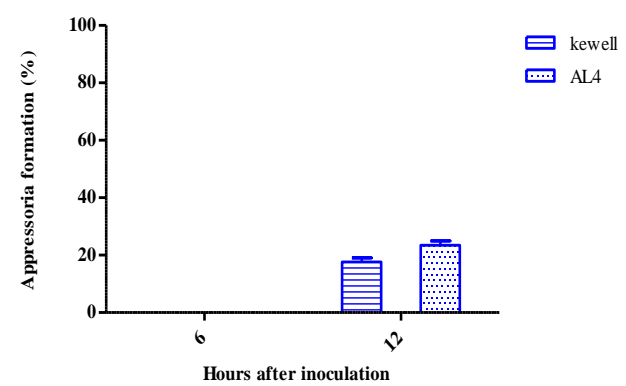

ILL7537 (R)

Fig. 3 Appressoria formation (\%) at 6 and 12 hours after inoculation 


\section{Histochemical detection of ROS generation in response to highly virulent isolate AL4}

$\mathrm{H}_{2} \mathrm{O}_{2}$ production caused by infection of AL4 was observed in ILL7537 at 24 hpi beneath the appressoria, however the frequency of this observation was far lower than for Kewell. Similarly, a far lower HR was observed in response to AL4 than Kewell in ILL5588 at 36 hpi (data not shown) and again no HR was observed in ILL6002.

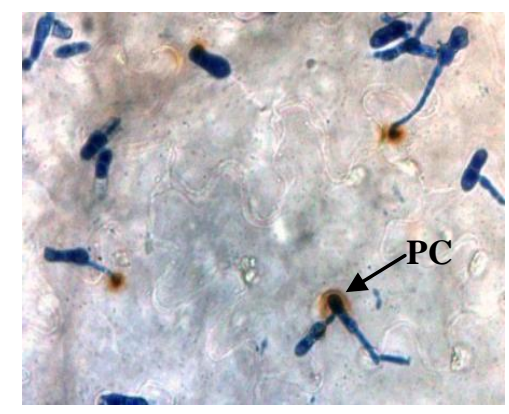

4A

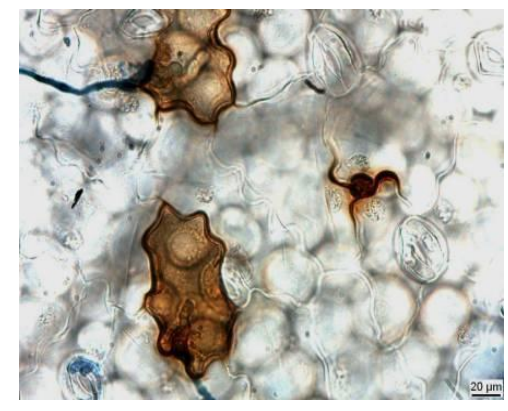

4B

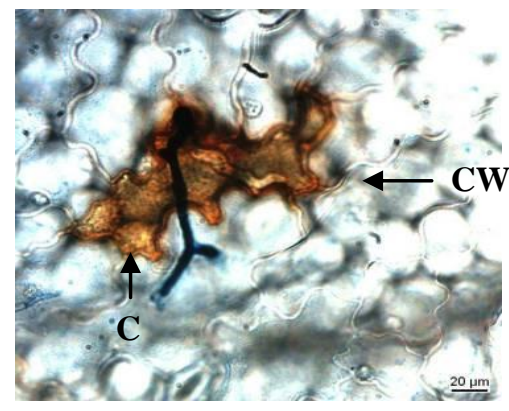

4C

Fig. 4 Production of ROS between 20 and 36 hpi in response to infection by A. lentis isolate Kewell on lentil genotype ILL7537. A. Early accumulation of phenolic compound (PC) beneath the appressoria (arrow) at 20 hpi.; B. Containment of PC at 28 hai C. HR at penetration sites along with typical characters of cell wall thickening (CWT) and cytoplasmic aggregation (CA) at $36 \mathrm{hpi}$.

\section{Discussion}

The reactions of the six lentil differential genotypes to infection by each isolate of A. lentis varied and corresponded broadly with the published phenotype of these genotypes, further confirming that these genotypes can be used for discriminating isolate virulence. Indeed, previous research had reproducibly shown that these lentil genotypes contained putatively different resistance mechanisms (or susceptibility) to A. lentis, enabling a sound basis for their inclusion in the differential host set (Nasir and Bretag 1997a, b; Ford et al., 1999; Nguyen et al., 2001; Rubeena et al., 2006). Six pathotypes of A. lentis were identified from 17 isolates collected within Australia, based on clear, descriptive and qualitative differences in disease symptoms on the six lentil genotypes. Furthermore, these results revealed that the time taken for the full expression of the disease symptoms during a controlled bioassay varied among host-isolate combinations. Since highly virulent isolates are able to cause disease symptoms on leaves faster than those of lower virulence, disease assessment prior to 21 days after inoculation may not correctly estimate potential isolate severity. The difference in the disease assessment at 7, 14 and 21 DAI was mainly to monitor the level of infection and discriminate the host reaction as previously reported by Ford et al. (1999) and Nguyen et al. (2001). ILL7537 was resistant to all of the isolates assessed as previously reported (Nasir and Bretag, 1997d; Nguyen et al., 2001). Therefore, the two major dominant resistance genes in ILL7537 (Nguyen et al. 2001) appeared to have wide stability across the A. lentis population and are of particular importance for resistance breeding. 
The Australian A. lentis isolates used in this study contained a high level of pathogenic variation as previously observed by Ford et al., (1999) and in Canada by Banniza and Vandenberg (2006). This is of considerable concern for lentil breeders, in breeding for reliably resistant varieties, since variation in virulence may lead to selective adaptation of the pathogen to overcome host resistance. This is particularly true since the teliomorph of Ascochyta lentis is known to exist in all growing regions of Australia (Kaiser, 1997; Galloway et al., 2004).

As previously stated clear evidence of qualitative difference in the infection ability between isolates and on a set of differential genotypes was required to indicate the existence of true pathotypes (Taylor and Ford, 2007). Quantitative difference in infection alone may reflect a natural distribution of aggressiveness within a population, ranging from low to high (Vail and Banniza, 2008).

\section{Qualitative and differential infection processes}

\section{Spore germination}

A major difference in the pre and post penetration behaviour among the low (Kewell) and high (AL4) virulence isolates of A. lentis was observed on leaves of the susceptible genotype ILL6002, the moderately resistant genotype ILL5588 and the resistant genotype ILL7537. Conidia germination is the first stage for the fungus to infect the plant tissues. Isolates with a higher germination percentage may possibly produce more appressoria and thus lead to more penetration events. Conidia of both isolates started germination by 2 hpi, with most germinated by $6 \mathrm{hpi}$, irrespective of isolate/host genotype combination, as was previously observed by Roundhill et al. (1995). The lower germination percentage observed in ILL7537 at 2 hpi, may suggest a recognition of pathogen activated molecular patterns (PAMPs; Zipfel, 2009; Pitzschke et al., 2009) resulting in the early switching on of defence responses. Basal defence compounds constitutively excreted on the plant surface may also have interfered with germination (Prats et al., 2007).

Although there was a significant difference in conidia germination percentage between the two isolates at $2 \mathrm{hpi}$, little to no variation in spore germination was observed at 6 and $12 \mathrm{hpi}$ irrespective of the isolate/host genotype combination, suggesting that virulence of the isolate may only be implicated in early spore germination. Similar findings were observed in the potato/Alternaria solani (Dita et al., 2007) and pea/Mycospharella pinoides (Nasir et al., 1992) pathosystems. Furthermore, AL4 may have produced compounds to block the activation of early defence mechanisms and may have also secreted enzymes/toxins to create a suitable environment for germination and further development, acting as virulence determinants (Jayakumar et al., 2005). In the related legume pathogen, A. rabiei, phytotoxin production was positively correlated with aggressiveness and was proposed to be an important pathogenicity factor in the chickpea/A. rabiei pathosystem (Jayakumar et al., 2005). Absence of host toxins in the susceptible cultivar ILL6002 may possibly have also led to greater successful spore germination by both isolates compared to the other resistant hosts. However, further research is required to uncover potential related responses in lentil.

\section{Germ tube growth}

The germ tube length varied significantly between host genotypes and isolates. AL4 isolate germ tubes grew vigorously compared to the Kewell isolate germ tubes, suggesting that germ tube length may have contributed to 
isolate virulence. This may also have been an indicator for isolate fitness, and in response to specific host receptivity. The recognition of non-specific elicitors released from the cell wall of the growing Kewell isolate may have been more readily recognised by the host. This may have led to the production of anti-microbial substances to inhibit the growth of germ tubes. Simultaneously, the pathogen may have reduced time to invasion as either an escape mechanism from plant surface attack and/or to speed up the reproductive cycle prior to further attack from the host.

Germ tube length of both isolates was reduced significantly in ILL7537 and ILL5588 compared to ILL6002. This may have been due to the activation of pathogenesis related (PR) proteins and other genes responsible for the restriction of fungal development (Conrath et al., 2001; Baysal et al., 2005). For example, PR 4, a chitinase is able to hydrolyse the fungal cell wall and thereby slow hyphae development. Apart from direct antifungal activity, PR proteins are also involved in resistance through release of oligomers from the fungal cell walls, which then act as elicitors for other vital defence responses (Esquerre-Tugaye et al., 2000). Similarly PR 10a has been shown to exhibit both ribonuclease and direct antifungal activity which was proposed to protect plants during programmed cell death (PCD; Liu and Ekramoddoullah, 2006). Both of these genes were previously found to be up-regulated in the resistance response of lentil to A. lentis (Mustafa et al, 2009; Vaghefi et al., 2013). Potential pathotype-specific defence mechanisms may be identified through further transcription analysis of the most differential host-isolate interactions. Indeed, identification of early response genes involved in compatible and incompatible interactions may help to select for conserved and specific lentil defence mechanism against $A$. lentis.

\section{Appressoria formation}

Appressoria formation is a necessary step for successful penetration that further leads to infection (Hohl et al., 1990; Ilarsan and Dolar, 2002). The low virulent isolate Kewell initiated appressoria formation after 12 hpi on all three genotypes, whereas AL4 formed appressoria quickly, by 6 hpi on ILL6002 and ILL5588. Although there was no significant difference in spore germination between the isolates at 12 hpi, AL4 developed a significantly higher number of appressoria than Kewell. Penetration by both isolates mostly occurred directly through the epidermal cell wall junctions on the leaf surface on all three host genotypes, indicating that the pathogen did not rely on detecting stomata through volatiles or other substances. However stomatal penetration was occasionally observed with AL4, but only on the susceptible genotype ILL6002. These findings are in agreement with observations by Hohl et al. (1990) and Ilarsan and Dolar (2002).

\section{Histochemical detection of reactive oxygen species (ROS) generation}

The distinct difference in ROS species production between the compatible and incompatible interaction at the early stages of the A. lentis infection also provided evidence of difference in pathogenicity. Both ILL7537 and ILL5588 induced $\mathrm{H}_{2} \mathrm{O}_{2}$ accumulation in response to the low virulent isolate Kewell, and only ILL7537 activated ROS production in response to the high virulent isolate AL4. However, timing, frequency and magnitude of ROS production varied according to the previously reported level of host resistance. Similar findings were observed by Foster-Hartnett et al. (2007), who identified early and strong $\mathrm{H}_{2} \mathrm{O}_{2}$ accumulation in a resistant 
genotype compared to in a moderately resistant and susceptible genotype in the Medicago truncatula/Erisyphe pisi pathosystem.

ILL7537 produced more $\mathrm{H}_{2} \mathrm{O}_{2}$ beneath the appressoria (attempted penetration sites) and at the infected epidermal cells when infected by Kewell compared to AL4 at the early stage of interaction. $\mathrm{H}_{2} \mathrm{O}_{2}$ also accumulated in the vesicles, which developed in the epidermal cells and successfully arrested the fungal development. This suggested that the elicited accumulation of $\mathrm{H}_{2} \mathrm{O}_{2}$ may have contributed to defence signalling and thereby stimulated other defence responses that limited the development of Kewell in ILL7537.

\section{Conclusion}

Pathogenic groups were identified in the Australian Ascochyta lentis population based on the reaction of $A$. lentis isolates on six lentil genotypes and pre-penetration events and early differences in defence responses in compatible and incompatible interactions between high and low virulent A. lentis isolates on three lentil genotypes. General defence responses were expressed more rapidly and extensively in the incompatible than in the compatible interaction. $\mathrm{H}_{2} \mathrm{O}_{2}$ accumulation was likely to be triggered following recognition of elicitors released from the low virulent isolate, leading to confinement of pathogen spread. The HR may also act as a signal for gene activation resulting in secretion of fungal penetration-inhibitory substances into the surrounding plant cell wall to arrest further penetration and spread.

In order to confirm or further determine the biological functions of the defence responses, exemplars of specific functional defence gene families should be identified and their expression patterns observed during the infection progress. These molecular responses could provide further evidence of specific and perhaps differential host defences among resistant genotypes and together with the physiological and biochemical data, would provide a much clearer understanding of the major defence mechanism in lentil to A. lentis pathotypes.

\section{Acknowledgements}

We thank Mr Michael Materne (Victorian Department of Environment and Primary Industries) for supply of seed and Mr Kurt Lindbeck (New South Wales Department of Primary Industries) for supply of isolates. 


\section{References}

Achuo, E.A., Audenaert, K., Meziane, H. and Hofte, M. (2004) The salicylic acid-dependent defence pathway is effective against different pathogens in tomato and tobacco. Plant Pathology, 53, 65-72.

Ahmed, S. and Morrall, R.A.A. (1996) Field reactions of lentil lines and cultivars to isolates of Ascochyta fabae f. sp. lentis. Canadian Journal of plant Pathology, 18, 362-369.

Banniza, S. and Vandenberg, A. (2006) Investigations into the population structure of Ascochyta lentis in western Canada. In Proceedings of the 1st International Ascochyta workshop on grain legumes. Le Tronchet, France.

Chen, W., McPhee, K.E. and Muehlbauer, F.J. (2005) Use of a mini-dome bioassay and grafting to study resistance of chickpea to ascochyta blight. Journal of Phytopathology, 153, 579-587.

Chongo, G., Gossen, B.D. and Bernier, C.C. (2002) Infection by Colletotricum truncatum in resistant and susceptible lentil genotypes. Canadian Journal of Plant Pathology, 24, 81-85.

Clulow, S.A., Lewis, B.G. and Matthews, P. (1992) Expression of resistance to Mycosphaerella pinodes in Pisum sativum. Plant Pathology, 41, 362-369.

Clulow, S.A., Matthews, P. and Lewis, B.G. (1991) Genetical analysis of resistance to Mycosphaerella pinodes in pea seedlings. Euphytica, 58, 183-189.

Coram , T.E. and Pang, E.C.K. (2005a) Isolation and analysis of candidate ascochyta blight defence genes in chickpea. Part I. Generation and analysis of an expressed sequence tag (EST) library. Physiological and Molecular Plant Pathology, 166, 192-200.

Damm, U., O’Connell, R.J., Crous, P.W., Groenewald, J.Z. (2014) The Colletotrichum destructivum species complex - hemibiotrophic pathogens of forage and field crops. Studies in Mycology 79, 49-84.

Ford, R., Pang, E.C.K., Taylor, P.W.J. (1999) Genetics of resistance to ascochyta blight (Ascochyta lentis) of lentil and the identification of closely linked RAPD markers. Theoretical and Applied Genetics, 98, 93-98.

Ford, R., Garnier-Gere, P.H., Nasir, M. and Taylor, P.W.J. (2000) Structure of Ascochyta lentis in Australia revealed with random amplified polymorphic DNA (RAPD) markers. Australasian Plant Pathology, 29, 36-45.

Foster-Hartnett, D., Dariush, D., Silvia, P., Natasha, S., Gabriella, E., Kathryn A, V., Nevin D, Y. and Deborah A, S. (2007) Molecular and cytological responses of Medicago truncatula to Erysiphe pisi. Molecular Plant Pathology, 8, 307-319. 
Hohl, B., Pfautsch, M. and Barz, W. (1990) Histology of disease development in resistant and susceptible cultivars of chickpea (Cicer arietinum L.) inoculated with spores of Ascochyta rabiei. Journal of Phytopathology, 129, 31-45.

Huckelhoven, R. (2007) Cell wall-associated mechanisms of disease resistance and susceptibility. Annual review of Phytopathology, 45, 101-127.

Huckelhoven, R., Fodor, J., Preis, C. and Kogel, K.H. (1999) Hypersensitive cell death and papilla formation in barley attacked by the powdery mildew fungus are associated with hydrogen peroxide but not with salicylic acid accumulation. Plant Physiology, 119, 1251-1260.

Huckelhoven, R. and Kogel, K.H. (2003) Reactive oxygen intermediates in plant-microbe interactions: Who is who in powdery mildew resistance? Planta, 216, 891-902.

Hussain, S., Nasir, M., Hanif, M. and Malik, B.A. (1999) Screening of lentil accessions against Ascochyta lentis. Pakistan Journal of Biological Science, 1, 101-102.

Ilarslan, H. and Dolar, F.S. (2002) Histological and ultrastructural changes in leaves and stems of resistant and susceptible chickpea cultivars to Ascochyta rabiei. Journal of Phytopathology, 150, 340-348.

Iqbal, S.M., Abdul, R.C.H. and Ali, S. (2006) Pathogenic variability among the isolates of Ascochyta lentis. International Journal of Agriculture and Biology, 8:5, 618-620.

Jayakumar, P., Gossen, B. D., Gan, Y. T., Warkentin, T. D. and Banniza, S. (2005) Ascochyta blight of chickpea: Infection and host resistance mechanisms. Canadian Journal of Plant Pathology, 27, 499-509.

Lamb, C. and Dixon, R.A. (1997) The oxidative burst in plant disease resistance. Annual Review of Plant Physiology and Plant Molecular Biology, 48, 251-275.

Muehlbauer, F. and Chen, W. (2007) Resistance to ascochyta blights of cool season food legumes. European Journal of Plant Pathology, 119, 135-141.

Nasir, M. and Hoppe, H. H. (1991) Studies on pathotype differentiation with Mycosphaerella pinodes (Berk. \& Bloxam) Vestergren, a component of the Ascochyta-disease-complex of peas (Pisum sativum L.). Journal of Plant Disease and Protection, 98, 619-626.

Nasir, M. (1998) Improvement of drought resistance in lentils in Nepal, Pakistan and Australia. Mid-term report 1995-1998. ACIAR Project PN-9436: Victorian Institute for Dryland Agriculture, Agriculture Victoria: Horsham, Victoria. 
Nasir, M. and Bretag, T.W. (1997a) Prevalence of Ascochyta fabae f. sp. lentis on lentil seed from Victoria, Australia. Australian Plant Pathology, 26, 117-120.

Nasir, M. and Bretag, T.W. (1997b) Variability in the virulence of Ascochyta fabae f. sp. lentis. In Proceeding of International Food Legume Research Conference III. Adelaide, Australia, pp. 160.

Nasir, M. and Bretag, T.W. (1997c) Resistance to Ascochyta fabae f. sp. lentis in lentil accessions. In Proceedings of International Food Legume Research Conference III. Adelaide, Australia, pp. 161.

Nasir, M. and Bretag, T.W. (1997d) Pathogenic variability in Australian isolates of Ascochyta lentis. Australasian Plant Pathology, 26, 217-220.

Nasir, M. and Bretag, T.W. (1998) Reactions of lentil accessions from 25 different countries to Australian isolates of Ascochyta lentis. Genetic Resources and Crop Evolution, 45, 297-299.

Nasir, M., Hoppe, H.H. and Ebrahim-Nesbat, F. (1992) The development of different pathotype groups of Mycosphaerella pinodes in susceptible and partially resistant pea leaves. Plant Pathology, 41, 187-194.

Nasir, M. (1998) Improvement of drought and disease resistance in lentil in Nepal, Pakistan and Australia. Midterm report 1995-1998: Victorian Institute for Dryland Agriculture, Agriculture Victoria: Horsham, Vic.

Nguyen, T.T., Taylor, P.W.J., Brouwer, J.B., Pang, E.C.K. and Ford, R. (2001) A novel source of resistance in lentil (Lens culinaris ssp. culinaris) to ascochyta blight caused by Ascochyta lentis. Australasian Plant Pathology, 30, 211-215.

Pitzschke A, S.A., Hirt H. (2009) MAPK cascade signalling networks in plant defence. Current Opinion in Plant Biology, 12, 421-426.

Roundhill, S., Fineran, B., Cole, A. and Ingerfeld, M. (1995) Structural aspects of Ascochyta blight of lentil. Canadian Journal of Botany, 73, 485-497.

Rubeena, Taylor, P.W.J., Ades, P.K. and Ford, R. (2006) QTL mapping of resistance in lentil (Lens culinaris ssp. culinaris) to ascochyta blight (Ascochyta lentis). Plant Breeding, 125, 506-512.

Russell, A.C. and Hill, G. (1997) Identification of lentil (Lens culinaris) with resistance to ascochyta blight and variation in host response to different pathotypes. In Proceedings of International Food Legume Research Conference III. Adelaide, Australia. pp. 162.

Taylor, P.W.J. and Ford, R. (2007) Diagnostics, genetic diversity and pathogenic variation of ascochyta blight of cool season food and feed legumes. European Journal of Plant Pathology, 119, 127-133. 
Taylor, P.W.J, Lindbeck, K., Chen, W. and Ford, R. (2007) Lentil Diseases. In: Lentil: An Ancient Crop for Modern Times Ed SS Yadav. Springer, pp 291-313.

Thordal-Christensen, H., Ziguo, Z., Yangdou, W. and David, B.C. (1997) Subcellular localization of $\mathrm{H}_{2} \mathrm{O}_{2}$ in plants. $\mathrm{H}_{2} \mathrm{O}_{2}$ accumulation in papillae and hypersensitive response during the barley-powdery mildew interaction. The Plant Journal, 11, 1187-1194.

Tivoli, B. and Banniza, S. (2007) Comparison of the epidemiology of ascochyta blights on grain legumes. European Journal of Plant Pathology, 119, 59-76.

Vail, S. and Banniza, S. (2008) Structure and pathogenic variability in Ascochyta rabiei populations on chickpea in the Canadian prairies. Plant Pathology, 57, 665-673.

Vaghefi, N., Mustafa, B.M., Dulal, N., Selby-Pham, J., Taylor P.W.J., and Ford, R. (2013) A novel pathogenesis-related protein (LcPR4a) from lentil, and it's involvement in defence against Ascochyta lentis. Phytopathologia Mediterranea 52 (1): 192-201.

Ye, G., McNeil, D.L. and Hill, G.D. (2002) Breeding for resistance to lentil Ascochyta blight. Plant Breeding, 121, 185-191.

Zipfel, C. (2009) Early molecular events in PAMP-triggered immunity. Current Opinion in Plant Biology, 12, 414-420. 


\section{University Library}

\section{- M M N E R VA A gateway to Melbourne's research publications}

Minerva Access is the Institutional Repository of The University of Melbourne

Author/s:

Sambasivam, P;Taylor, PWJ;Ford, R

Title:

Pathogenic variation and virulence related responses of Ascochyta lentis on lentil

Date:

2017-02-01

Citation:

Sambasivam, P., Taylor, P. W. J. \& Ford, R. (2017). Pathogenic variation and virulence related responses of Ascochyta lentis on lentil. EUROPEAN JOURNAL OF PLANT PATHOLOGY, 147 (2), pp.265-277. https://doi.org/10.1007/s10658-016-0999-2.

Persistent Link:

http://hdl.handle.net/11343/282815 